\title{
A systematic review of randomized trials comparing revascularization rate and graft patency of off-pump and conventional coronary surgery
}

Eric Lim, FRCS (C-Th), ${ }^{\text {a }}$ Andrew Drain, MRCS, ${ }^{a}$ William Davies, MRCS, ${ }^{a}$ Lyn Edmonds, MCLIP, ${ }^{\text {b }}$ and Bruce R. Rosengard, FRCS $^{\text {a }}$

Earn CME credits at http:// cme.ctsnetjournals.org
From the Department of Cardiothoracic Surgery ${ }^{\mathrm{a}}$ and the Library and Knowledge Services, ${ }^{\mathrm{b}}$ Papworth Hospital, Cambridge, United Kingdom.

Presented to the Society of Cardiothoracic Surgeons of Great Britain and Ireland Annual Meeting, Dublin, Ireland, March 14,2006

Received for publication June 15, 2006; revisions received July 24, 2006; accepted for publication Aug 8, 2006.

Address for reprints: Mr Eric Lim, Department of Cardiothoracic Surgery, Papworth Hospital, Papworth Everard, Cambridge CB3 8RE, United Kingdom (E-mail: eric. lim@cvsnet.org).

J Thorac Cardiovasc Surg 2006;132:1409-13 $0022-5223 / \$ 32.00$

Copyright (c) 2006 by The American Association for Thoracic Surgery

doi:10.1016/j.jtcvs.2006.08.012
Objective: Although many trials have been conducted to evaluate the benefits of off-pump coronary surgery, few have concentrated on graft patency. We sought to evaluate the impact of off-pump surgery on completeness of revascularization and graft patency compared with conventional surgery.

Methods: A systematic literature search was undertaken of all randomized trials of off-pump coronary surgery in MEDLINE, EMBASE, the Cochrane Library Controlled Trials Register, the National Research Register, and abstracts from major conferences.

Results: In total, 132 publications were identified. From this number, we excluded 43 without a conventional surgery arm and 80 that did not evaluate graft patency. One trial was excluded for selective angiography and one abstract was excluded because of insufficient information. A total of 7 trials were eligible for overview. On initial analysis, the relative risk of graft patency in off-pump coronary surgery compared with conventional surgery was 0.959 (95\% confidence interval 0.936 $0.983 ; P=.001)$. The analysis was repeated after excluding one specific trial because of clinical and statistical heterogeneity $\left(\chi^{2}{ }_{6}=27.78 ; P<.001\right)$, and a relative risk of 0.953 (95\% confidence interval $0.927-0.980 ; P=.001$ ) was obtained with no further evidence of heterogeneity $\left(\chi^{2}{ }_{5}=5.35 ; P=.374\right)$. In 5 trials that included the mean number of grafts performed per arm, the standardized mean difference in revascularization comparing off-pump with conventional surgery was -0.164 ( -0.286 to $-0.043 ; P=.008)$.

Conclusion: In a meta-analysis of randomized trials, patients undergoing off-pump coronary surgery had a lower rate of revascularization and lower graft patency than did patients undergoing conventional coronary surgery.

$\mathrm{E}$ nthusiasm for off-pump coronary artery bypass surgery has been ignited by concerns of the adverse effects of cardiopulmonary bypass that is used to support the circulation while the heart is stopped to perform the microvascular anastomoses. In 2003, the hope of reducing possible complications associated with cardiopulmonary bypass has encouraged cardiac surgeons to perform $17 \%$ of coronary operations in the United Kingdom and $21 \%$ of coronary operations in the United States without the use of cardiopulmonary bypass. ${ }^{1}$

Many trials have been conducted to evaluate the benefits of off-pump coronary surgery, but few have concentrated on safety. A fundamental aim of coronary surgery is to fashion a perfect anastomosis to deliver blood to the ischemic territories of the myocardium. Unlike conventional techniques that use cardiopulmonary bypass, microvascular anastomoses performed on the beating heart without aortic crossclamping can result in a degree of movement and native coronary blood flow that may obscure the operative field. The heart may less amenable to manip- 
ulation with a ventricle that is tense with blood, and therefore optimum positioning may need to be balanced against the ability to achieve satisfactory cardiac output.

As off-pump surgery becomes more popular, the evaluation of the impact of the aforementioned technical factors on vascular graft patency and the ability to achieve complete revascularization compared with convention surgery is imperative.

\section{Methods}

We performed a systematic review and meta-analysis of randomized trials comparing off-pump and conventional coronary surgery.

\section{Search Strategy}

A systematic literature search was undertaken of MEDLINE (1966 to October 2005), EMBASE (1974 to October 2005), and the Cochrane Library 2005, Issue 4 . To maximize the sensitivity of the search strategy, we aimed to identify all published and unpublished randomized trials of off-pump coronary surgery (Appendix A). Where available, abstracts from major cardiology and cardiothoracic surgery scientific meetings from 2003 to 2005 were handsearched. Reference lists of all relevant studies were reviewed and attempts were made to contact authors of previous trials.

\section{Study Selection}

All randomized controlled trials evaluating off-pump coronary surgery were included. No restrictions were placed on abstracts, conference proceedings, or language. Our exclusion criteria included trials that did not include a conventional surgery arm, trials that did not report vascular graft patency as an outcome, and trials of selective coronary angiography. A given patient population was used only once; if the same population appeared in other publications, the article that provided the most complete follow-up angiographic data was selected. We did not assume that technical factors would only influence early graft patency; therefore, if vascular graft patency was assessed on more than one occasion, the results at the longest follow-up were used. Our rationale is that the background factors influencing graft patency are constant and assumed to be equal in both arms because of randomization, whereas the time interval involving differences in operative technique that might affect vascular graft patency is unknown. Individual studies were evaluated on blind assessment of outcome, expertise of surgeons, and number of patients undergoing angiography.

\section{Data Abstraction}

Two investigators independently assessed articles according to the predetermined eligibility criteria, and discordances were resolved by consensus review. Graft patency was evaluated by angiography in all the trials. Where means were reported, ${ }^{2,3}$ the results were transformed into absolute numbers by multiplication with the total number of patients who underwent angiography.

\section{Statistical Methods}

Meta-analysis was performed by combining the results of graft patency of off-pump compared with conventional coronary surgery. A fixed effects model was chosen on the assumption that variation in the individual trial results occur about a true mean.
Sensitivity analysis was performed by repeating the analysis using a random effects model, excluding data from abstracts, and using early data in trials that reported more than one time point for graft patency. Statistical heterogeneity of trial results was tested by the $\chi^{2}$ test of homogeneity and also expressed as $\mathrm{I}^{2}$ : the proportion of total variability attributed to the individual trials as a measure of inconsistency between studies (a value of $25 \%$ or less is regarded as low $).{ }^{4}$ All statistical analyses were performed with Stata 8.2 (StataCorp, College Station, Tex).

\section{Results}

\section{Trial Flow, Characteristics, and Quality Appraisal}

Our search strategy identified 132 publications, of which 43 were excluded for not including a conventional surgery comparison arm, 80 were excluded owing to failure to report graft patency as an outcome, 1 was excluded for selective angiography, ${ }^{5}$ and the results from 1 abstract was not able to be included because it did not detail sufficient information for data abstraction. ${ }^{6}$ No trials were excluded on the sole basis of duplication of reporting of graft patency.

Finally, the results from 7 published trials were identified as eligible for overview and included in the meta-analysis (Tables 1 and 2). One was a single surgeon series, ${ }^{7} 1$ had two participating surgeons, ${ }^{8} 2$ had four participating surgeons, ${ }^{3,9} 1$ had five participating surgeons, ${ }^{10}$ and in the rest, the number of surgeons was not stated. Analysis was by intention-to-treat in 6 trials, ${ }^{3,7-11}$ and the method of analysis was unstated in the remaining. Intention-to-graft with a prespecified index was stated in 3 trials, ${ }^{3,8,11}$ Blind assessment of outcome was stated in 5 trials. ${ }^{3,7,8,10,11}$ The use of systemic heparinization in the off-pump surgical arms was stated in 3 trials with a dose of a half ${ }^{8}$ and a third ${ }^{3,9}$ of that used for cardiopulmonary bypass. Two trials used arterial grafts exclusively, ${ }^{2,10}$ and 1 trial exclusively used a composite inflow technique ${ }^{2}$ (in which all the grafts originated from the internal thoracic artery, without the use of aortacoronary proximal anastomoses). Three trials stated a specific criterion for graft patency (Fitzgibbon A or B). ${ }^{7,10,11}$

\section{Meta-analysis}

The initial analysis included all 7 trials and obtained a relative risk of graft patency in off-pump coronary surgery compared with conventional surgery of 0.959 (95\% confidence interval $0.936-0.983 ; P=.001)$. However, there was evidence to suggest clinical and statistical heterogeneity of trial results $\left(\chi_{6}^{2}=27.78 ; P<.001\right)$. The variation in relative risk attributable to heterogeneity $\left(\mathrm{I}^{2}\right)$ was $78.4 \%$. The heterogeneity resulted from the inclusion of a clinical trial of total arterial revascularization exclusively with composite inflow, ${ }^{2}$ whereas in the remaining trials most or all the proximal anastomoses were performed onto the ascending aorta. The single trial using exclusive composite inflow grafting ${ }^{2}$ was then excluded from further analyses of graft patency. 


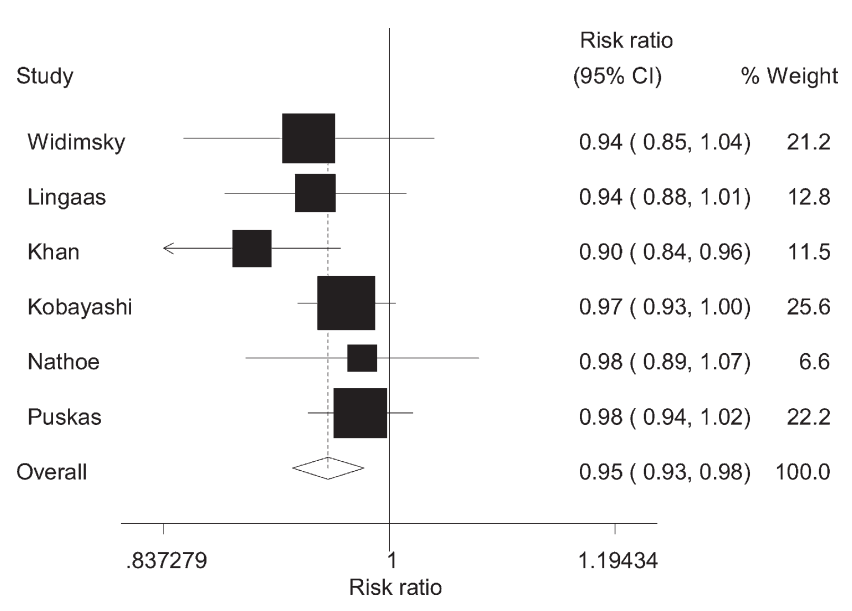

Figure 1. Relative risk of graft patency comparing off-pump with conventional coronary surgery.

In the remaining 6 trials, the relative risk of graft patency in off-pump coronary surgery compared with conventional surgery was 0.953 (95\% confidence interval 0.927-0.980; $P=.001$, Figure 1), with no evidence to suggest statistical heterogeneity $\left(\chi_{5}^{2}=5.35 ; P=.374\right)$. The variation in relative risk attributable to heterogeneity $\left(\mathrm{I}^{2}\right)$ was reduced to $6.6 \%$.

Results from the sensitivity analyses were similar. With a random effects model, the relative risk was 0.958 (0.935$0.982 ; P=.001)$. When early graft patency results were substituted in the 2 trials that evaluated in-hospital ${ }^{7}$ and intraoperative angiography, ${ }^{9}$ the relative risk was 0.971 (0.947-0.995; $P=.016)$ with significant heterogeneity $\left(\chi_{5}^{2}=25.95, P<.001 ; \mathrm{I}^{2}\right.$ of $\left.80.7 \%\right)$.

In the 6 trials that included the mean and standard deviation of the number of grafts performed per arm, ${ }^{2,7-11}$ the standardized mean difference in revascularization comparing off-pump with conventional coronary surgery was -0.164 ( -0.286 to $-0.043 ; P=.008$, Figure 2$)$. There was no evidence to suggest heterogeneity of trial results with regard to mean number of distal anastomoses $\left(\chi^{2}{ }_{4}=3.68\right.$; $P=.596)$. The variation in relative risk attributable to heterogeneity $\left(\mathrm{I}^{2}\right)$ was $0 \%$.

\section{Discussion}

Whereas excellent results have been published for off-pump coronary surgery, most of the studies were nonrandomized. Until now, it remains uncertain whether the outcome of off-pump coronary surgery is similar to that of conventional surgery with the use of cardiopulmonary bypass. ${ }^{12}$

Previous meta-analyses suggested lower rates of mycoardial infarction, stroke, atrial fibrillation, and wound infection with off-pump coronary surgery ${ }^{13}$; however, the results are influenced by inclusion of 43 nonrandomized studies out

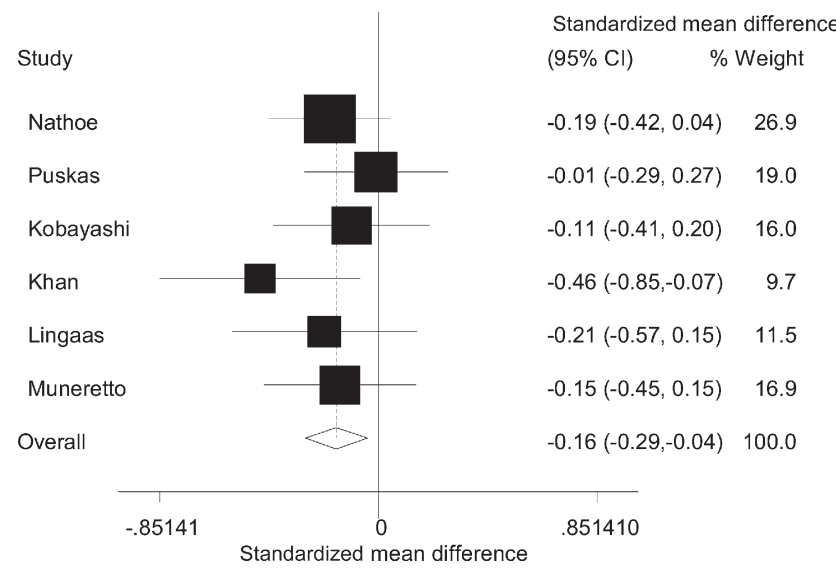

Figure 2. Standardized mean difference in the number of grafts performed in trials of off-pump compared with conventional coronary surgery.

of the 53 that were analyzed. When only randomized trials were included, a favorable but not statistically significant composite of death, stroke, and myocardial infarction was reported in patients undergoing off-pump coronary surgery. ${ }^{14}$ The same message was reverberated by meta-analyses of individual end points (of randomized trials); there were no significant differences in major outcomes such as mortality, stroke, myocardial infarction, and renal failure, but improvement was noted in selected outcomes such as lower transfusion and inotrope requirements, fewer respiratory infections, and shorter ventilation time, intensive care stay, and hospital stay. ${ }^{15,16}$

Reflective of the focus of previous studies, existing metaanalyses have focused mainly on clinical benefits. However, we have chosen to focus on safety, with an outcome that most closely reflects the technical aspects of the differences in two operative techniques, using meta-analysis to obtain insights into a question that could not be adequately addressed by small existing studies. Our results highlight that the patients in the off-pump surgery arms of clinical trials (on average) received fewer grafts and had a poorer patency rate than did their counterparts undergoing conventional coronary surgery.

We are aware of a number of nuances specific to trials evaluating off-pump surgery. It is not possible for the studies (surgeon) to be double blind, and the reporting of trial results is usually undertaken by enthusiasts of off-pump surgery. Individually, the randomized trials were underpowered to detect small differences in graft patency, but most authors concluded similar patency rates between the two surgical techniques, except in one trial in which the difference reached statistical significance. ${ }^{8}$

As with all surgical trials, the results are influenced by the level of experience of the surgeon. Currently, the evi- 
TABLE 1. Trial characteristics

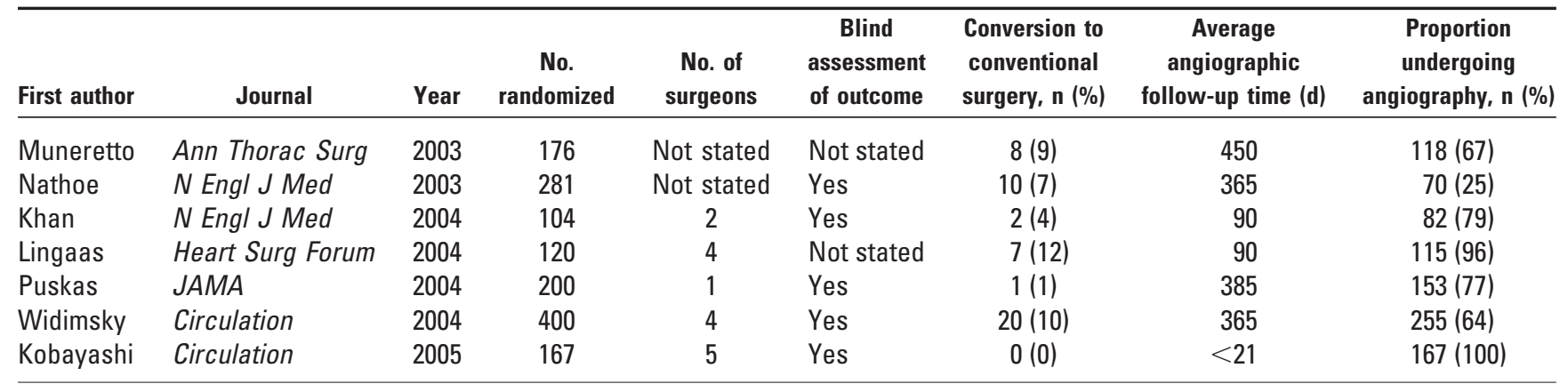

dence generated from randomized trials of off-pump surgery represents data acquired from only a handful of surgeons. It is difficult to determine how applicable the results are to a population of cardiac surgeons with different levels of experience and ability, and the overall results of lower graft patency achieved mostly by the experts in the field is disconcerting. The pooled results revealing lower graft patency remained robust to the different assumptions as tested by sensitivity analysis.

Although it is temping to conclude that a single large trial should be conducted, we consider the results of several small to medium-sized trials performed by different surgeons in different patient populations, all yielding similar reductions in graft patency (2\%-10\%), to be more convincing, because the results were consistent despite the presence of greater variability. Certainly, if further trials are planned, researchers should consider calculating the sample size on the basis of an equivalence design as opposed to a noninferiority design such that important differences can be detected if they exist. Further trials would help to determine whether comparative patency improves with time and whether our findings remain consistent with the results from an increasing pool of surgeons.

\section{Potential Limitations}

Owing to insufficient data, we were unable to perform a subanalysis for differences in patency rates in the different vascular territories of the heart or by conduit type. However, poorer graft patency has been reported in the left anterior descending territory ${ }^{8}$ as well as in non-left anterior descending territories. ${ }^{3}$ As all data were abstracted from randomized trials, it is assumed that the patients in both arms had a similar distribution of coronary disease.

Each graft unit is not independent. The factors affecting graft patency that are constant within each individual can vary between individuals (clustering). However, the same degree of error is assumed to exist between both arms of a randomized trial, negating any nondifferential effects. Only one trial adjusted for clustering by use of a generalized estimating equation. ${ }^{7}$ Expressing count data (number of grafts) as a mean value is not ideal owing to the necessary distributional assumptions. However, that was the summary statistic provided by all trials.

\section{Clinical Implications}

Our results do not suggest that off-pump coronary surgery should be abandoned. Selective indications may exist, such as the porcelain (heavily calcified) aorta in which off-pump revascularization may avert extensive concomitant aortic surgery.

However, the potential benefits of off-pump surgery need to be interpreted in light of reduced revascularization, reduced graft patency, the impact of reduced graft patency on long-term survival, ${ }^{16}$ and reports of increased repeat inter-

TABLE 2. Revascularization and graft patency outcomes

\begin{tabular}{|c|c|c|c|c|c|c|c|c|c|c|}
\hline \multirow[b]{2}{*}{ Author } & \multicolumn{2}{|c|}{$\begin{array}{l}\text { No. analyzed } \\
\text { in each arm }\end{array}$} & \multicolumn{2}{|c|}{$\begin{array}{l}\text { Mean (SD) no. of grafts } \\
\text { performed }\end{array}$} & \multicolumn{2}{|c|}{$\begin{array}{l}\text { No. who underwent } \\
\text { angiography (\%) }\end{array}$} & \multicolumn{2}{|c|}{$\begin{array}{l}\text { No. of distal } \\
\text { anastomoses }\end{array}$} & \multicolumn{2}{|c|}{$\begin{array}{l}\text { No. of patent } \\
\text { anastomoses }\end{array}$} \\
\hline & Off & $0 \mathrm{n}$ & Off & On & Off & On & Off & On & Off & On \\
\hline Muneretto & 88 & 88 & $2.7(0.5)$ & $2.8(0.8)$ & $60(68)$ & $58(66)$ & 162 & 162 & 161 & 161 \\
\hline Nathoe & 142 & 139 & $2.4(1.0)$ & $2.6(1.1)$ & $28(20)$ & $42(30)$ & 69 & 89 & 63 & 83 \\
\hline Khan & 54 & 50 & $3.1(0.6)$ & $3.4(0.7)$ & $43(80)$ & $39(78)$ & 130 & 130 & 114 & 127 \\
\hline Lingaas* & 60 & 60 & $2.6(0.9)$ & $2.8(1.0)$ & $60(100)$ & $60(100)$ & 140 & 163 & 124 & 153 \\
\hline Puskas & 98 & 99 & $3.4(1.04)$ & 3.4 (1.08) & $76(78)$ & $77(78)$ & 251 & 260 & 235 & 249 \\
\hline Widimsky & 208 & 192 & $2.3(\mathrm{~N} / \mathrm{A})$ & $2.7(\mathrm{~N} / \mathrm{A})$ & $123(59)$ & 132 (69) & 283 & 356 & 197 & 264 \\
\hline Kobayashi & 81 & 86 & $3.5(1.00)$ & $3.6(0.9)$ & $80(100)$ & 78 (100) & 280 & 305 & 261 & 294 \\
\hline
\end{tabular}

$S D$, Standard deviation. *Number who underwent angiography was reported as 60 in each arm despite only 115 undergoing angiography. 
ventions. ${ }^{13,17}$ Off-pump practitioners should be encouraged to audit their outcomes because surgical results from existing randomized trials performed by a handful of experts may not necessarily be applicable to their practice.

\section{Conclusions}

In a meta-analysis of randomized trials, patients undergoing off-pump coronary surgery had a lower rate of revascularization and lower graft patency than did patients undergoing conventional coronary surgery.

\section{References}

1. Keogh BE, Kinsman R. The Society of Cardiothoracic Surgeons of Great Britain and Ireland. Fifth National Adult Cardiac Surgical Database Report 2003. Oxfordshire: Dendrite Clinical Systems Ltd; 2004.

2. Muneretto C, Bisleri G, Negri A, Manfredi J, Metra M, Nodari S, et al. Off-pump coronary artery bypass surgery technique for total arterial myocardial revascularization: a prospective randomized study. Ann Thorac Surg. 2003;76:778-82; discussion 783.

3. Widimsky P, Straka Z, Stros P, Jirasek K, Dvorak J, Votava J, et al. One-year coronary bypass graft patency: a randomized comparison between off-pump and on-pump surgery. Angiographic results of the PRAGUE-4 trial. Circulation. 2004;110:3418-23.

4. Higgins JP, Thompson SG, Deeks JJ, Altman DG. Measuring inconsistency in meta-analyses. BMJ. 2003;327:557-60.

5. Czerny M, Baumer H, Kilo J, Zuckermann A, Grubhofer G, Chevtchik $\mathrm{O}$, et al. Complete revascularization in coronary artery bypass grafting with and without cardiopulmonary bypass. Ann Thorac Surg. 2001;71:165-9.

6. Al-Ruzzeh S, George S, Bustami M, Kemp M, Chambers J, Wray J, et al. Clinical and angiographic outcomes of coronary artery bypass grafting with and without cardiopulmonary bypass: Harefield prospective randomized trial. Circulation. 2004;110(Suppl):III546.

7. Puskas JD, Williams WH, Mahoney EM, Huber PR, Block PC, Duke PG, et al. Off-pump vs conventional coronary artery bypass grafting: early and 1-year graft patency, cost, and quality-of-life outcomes-a randomized trial. JAMA. 2004;291:1841-9.

8. Khan NE, De Souza A, Mister R, Flather M, Clague J, Davies S, et al. A randomized comparison of off-pump and on-pump multivessel coronary-artery bypass surgery. $N$ Engl J Med. 2004;350:21-8.

9. Lingaas PS, Hol PK, Rein KA, Tonnesen TI, Svennevig JL, Hauge SN, et al. Clinical and angiographic outcome of coronary surgery with and without cardiopulmonary bypass: a prospective randomized trial. Heart Surg Forum. 2004;7:37-41.

10. Kobayashi J, Tashiro T, Ochi M, Yaku H, Watanabe G, Satoh T, et al. Early outcome of a randomized comparison of off-pump and on-pump multiple arterial coronary revascularization. Circulation. 2005;112 (9 suppl):I-338-43.

11. Nathoe HM, van Dijk D, Jansen EW, Suyker WJ, Diephuis JC, van Boven WJ, et al. A comparison of on-pump and off-pump coronary bypass surgery in low-risk patients. $N$ Engl J Med. 2003;348:394-402.

12. Sellke FW, DiMaio JM, Caplan LR, Ferguson TB, Gardner TJ, Hiratzka LF, et al. Comparing on-pump and off-pump coronary artery bypass grafting: numerous studies but few conclusions: a scientific statement from the American Heart Association council on cardiovascular surgery and anesthesia in collaboration with the interdisciplinary working group on quality of care and outcomes research. Circulation. 2005;111:2858-64.

13. Reston JT, Tregear SJ, Turkelson CM. Meta-analysis of short-term and mid-term outcomes following off-pump coronary artery bypass grafting. Ann Thorac Surg. 2003;76:1510-5.

14. Parolari A, Alamanni F, Cannata A, Naliato M, Bonati L, Rubini P, et al. Off-pump versus on-pump coronary artery bypass: meta-analysis of currently available randomized trials. Ann Thorac Surg. 2003;76: $37-40$.

15. Cheng DC, Bainbridge D, Martin JE, Novick RJ. Does off-pump coronary artery bypass reduce mortality, morbidity, and resource utilization when compared with conventional coronary artery bypass? a meta-analysis of randomized trials. Anesthesiology. 2005;102:188203.

16. Liao L, Kong DF, Shaw LK, Sketch MH Jr, Milano CA, Lee KL, et al. A new anatomic score for prognosis after cardiac catheterization in patients with previous bypass surgery. J Am Coll Cardiol. 2005;46: 1684-92.

17. Wijeysundera DN, Beattie WS, Djaiani G, Rao V, Borger MA, Karkouti K, et al. Off-pump coronary artery surgery for reducing mortality and morbidity: meta-analysis of randomized and observational studies. J Am Coll Cardiol. 2005;46:872-82.

\section{Appendix A. Search Strategy}

The Following Search Strategy Was Used for the

Cochrane Library:

\#1 MeSH descriptor CORONARY ARTERY BYPASS explode all trees, \#2 coronary NEAR bypass, \#3 coronary NEXT surgery, \#4 coronary NEXT artery NEXT surgery, \#5 cabg, \#6 aortocoronary NEXT bypass, \#7 coronary NEAR graft, \#8 (\#1 OR \#2 OR \#3 OR \#4 OR \#5 OR \#6 OR \#7) \#9 opcab, \#10 opcab, \#11 off NEXT pump, \#12 off-pump, \#13, off-pump, \#14 beating-heart, \#15 beating NEXT heart, \#16 (\#9 OR \#10 OR \#11 OR \#12 OR \#13 OR \#14 OR \#15), \#17 (\#8 AND \#16). This strategy was modified for use on the other databases.

\section{The Following Search Strategy Was Used for MEDLINE:}

\#1 MeSH descriptor CORONARY ARTERY BYPASS explode all trees, \#2 coronary NEAR bypass, \#3 coronary NEXT surgery, \#4 coronary NEXT artery NEXT surgery, \#5 cabg, \#6 aortocoronary NEXT bypass, \#7 coronary NEAR graft, \#8 (\#1 OR \#2 OR \#3 OR \#4 OR \#5 OR \#6 OR \#7) \#9 opcab, \#10 opcab, \#11 off NEXT pump, \#12 off-pump, \#13, off-pump, \#14 beating-heart, \#15 beating NEXT heart, \#16 (\#9 OR \#10 OR \#11 OR \#12 OR \#13 OR \#14 OR \#15), \#17 (\#8 AND \#16) AND PT=RANDOMIZEDCONTROLLED-TRIAL.

\section{The Following Search Strategy Was Used for EMBASE:}

\#1 Emtree descriptor CORONARY ARTERY BYPASS GRAFT, \#2 Emtree descriptor CORONARY ARTERY BYPASS SURGERY, \#3 Emtree descriptor OFF PUMP CORONARY SURGERY, \#4 (\#1 OR \#2 OR \#3) AND CLINICAL-TRIAL. No language limitations were applied. 